\title{
Energy flexibility in residential buildings clusters
}

\author{
Alice Mugnini ${ }^{1, *}$, Fabio Polonara ${ }^{1,2}$, and Alessia Arteconi ${ }^{3,1}$ \\ ${ }^{1}$ Università Politecnica delle Marche, Dipartimento di Ingegneria Industriale e Scienze Matematiche, \\ Via Brecce Bianche 12, 60131, Ancona, Italy \\ ${ }^{2}$ Consiglio Nazionale delle Ricerche, Istituto per le Tecnologie della Costruzione, Viale Lombardia \\ 49, 20098, San Giuliano Milanese (MI), Italy \\ ${ }^{3}$ KU Leuven, Department of Mechanical Engineering, B-3000, Leuven, Belgium
}

\begin{abstract}
The building sector represents one of the most energy-consuming worldwide and a great part of its consumption is accounted for residential demand for space heating and cooling. Although it is necessary to promote the buildings energy efficiency, energy flexibility is also of paramount importance to optimize the balance between demand and supply. In fact, an energy flexible building is defined as able to change, in a planned manner, the shape of its energy demand curve, electrical and thermal, while the comfort of the end-users is still guaranteed. Objective of this work is to exploit the energy demand management ability of different buildings composing a cluster, when their aggregated demand derived from electric heating systems (i.e. heat pumps) is subject to demand response (DR) strategies. Users with different occupancy profile are considered. By supposing to be able to activate the energy flexibility of the single building with thermostatic load control, different scenarios of cluster composition are evaluated in order to provide guidelines to implement optimal strategies for energy flexibility exploitation without drawback effects connected to the event.
\end{abstract}

\section{Introduction}

The high dissemination of non-programmable Renewable Energy Sources (RES) enforces the adoption of innovative solutions to reliably balance energy demand and supply. One of the most suggested is Demand Side Management (DSM) for which it is meant the planning, implementation and monitoring of utility activities that are designed to influence customer use of electricity [1]. In this scenario, a great contribution can be provided by the buildings sector. Buildings are responsible for about $28 \%$ of worldwide energy-related $\mathrm{CO}_{2}$ emissions, two-thirds of which is attributable to emissions from electricity generation for use in buildings [2]. It is clear that, if this demand becomes flexible and adaptable to grid requirements, it could be used to stabilize the electrical system.

According to IEA EBC Annex 67, the energy flexibility of a building is the ability to manage its demand and generation according to local climate conditions, user-needs, and energy network requirements [3]. Buildings can activate energy flexibility services in different ways: from charging and discharging of electric vehicle batteries, from load

\footnotetext{
* Corresponding author: a.mugnini@pm.univpm.it
} 
management of the Heating, Ventilation and Air Conditioning (HVAC) systems coupled with Thermal Energy Storages (TES) or from plug-in loads shifting [3]. However, when the HVAC is involved, the energy flexibility is provided by Thermostatically Controlled Loads (TCL) [4]. TCL represent one of the most explored flexibility sources in residential buildings, as a result of the growing diffusion of electric heating and cooling systems (e.g. heat pumps) [5] and the different thermal inertia levels that can be used in them (e.g. the thermal mass or a dedicated devices in addition to the heating/cooling distribution system). Many studies are available in literature concerning the quantification of this energy flexibility potential in single buildings when TCL are bounded to short-term variations in electricity demand (Demand Response strategies, DRs) [6]. D'Ettorre et al. [7] compared in term of energy costs the impact of the addition of thermal energy storage (TES) in a residential building with an air-source heat pump during load-shifting programs. A method for ranking buildings based on their capability to manage TCL was also introduced by Arteconi et al. [8]. In this work, the role of the design characteristics of a building and its HVAC system was assessed, showing great energy flexibility reserve in buildings with high thermal inertia. Tuner et al. [9] applied a pre-cooling strategy to produce peak-shaving in a residential building, demonstrating that between the $50 \%$ and the $99 \%$ of annual peak cooling electricity can be shifted off-peak.

Anyway, although in single buildings the TLC-shifting potential is widely substantiated, fewer studies focus on energy flexibility at building cluster level [10]. However, an optimized design of a cluster of buildings can allow both to dispose of large quantities of shiftable energy, and to avoid side effects before and after a short-term DR event. Indeed, to unlock the flexibility, a controller acts often on the HVAC thermostat to pre-heat or pre-cool the thermal mass. In this case, even if comfort continues to be guaranteed, possible drawback effects in load profile could occur with new power peaks anticipated or delayed.

The aim of this work is to highlight the importance of a differentiated users cluster, when the energy flexibility wants to be used without any drawback effects connected to it. In residential buildings users can be distinguished based on: (i) demand size (related to building thermal and physical characteristics), (ii) type of heating/cooling system or (iii) occupancy profile. The influence of the latter feature is analysed in this paper.

By simulating a residential building in heating season, users with different occupancy behaviour are modelled. To use the energy flexibility of TCL, the thermostat setpoints are managed to activate the thermal mass of the buildings. The combination of users with differentiated occupancy profiles is compared to a reference scenario during a peak-shaving strategy. Results shows that, a careful planning of the cluster based on the occupancy profile of users can have positive effects to realize TCL peak shaving event ensuring user comfort and avoiding new peaks arising from it.

\section{Methods}

To activate the energy flexibility obtainable from TCL, a short-term demand response event is introduced. It consists in the application of a peak-shaving strategy to reduce in the peak-hour the electricity demand derived from the heating system of a residential buildings cluster. The programmed abatement is possible thanks the exploitation of an allowed comfort band by the heating thermostat for each user in the cluster. As described is Section 2.1, the energy demand of the single building is modelled in MATALB with a lumped-parameter model based on the thermal-electricity analogy. While in Section 2.2, the heating system model is presented. Finally, the DR event applied to the buildings cluster is described in Section 2.3. 


\subsection{Single user energy demand}

To model the energy demand of the single user, a third order lumped-parameter model based on the thermal-electricity analogy is selected [11]. The RC-network is showed in Figure 1. The parameters of the system are identified according to the thermal and geometrical characteristics of the building with a white-box approach. In this way, all the parameters $\left(C_{m e}, C_{a}, C_{m i}, R_{\text {mee }}, R_{\text {mei }}, R_{\text {mii }}, R_{\text {inf }}\right.$ and $\left.R_{w}\right)$ have a physical meaning. Starting from the thermal capacitances, $C_{a}$ represents the indoor air node while $C_{m e}$ and $C_{m i}$ reproduce respectively the external and the internal thermal mass of the building. Their numerical values are selected in agreement with the UNI EN ISO 13790 [12]. As concern the thermal resistances, $\mathrm{R}_{\mathrm{w}}$ and $\mathrm{R}_{\mathrm{inf}}$ represent the heat transfer between the indoor $\left(T_{\mathrm{a}}\right)$ and the outdoor air temperature $\left(T_{\mathrm{o}}\right)$ due to windows and infiltrations. $\mathrm{R}_{\text {mee }}$ models the heat flux between the external thermal mass of the building $\left(T_{\mathrm{me}}\right)$ and the outdoor temperature $\left(T_{\mathrm{o}}\right)$, while $\mathrm{R}_{\mathrm{mei}}$ and $\mathrm{R}_{\text {mii }}$ are the thermal resistances between the indoor air temperature $\left(T_{\mathrm{a}}\right)$ and the external $\left(T_{\mathrm{me}}\right)$ and internal $\left(T_{\mathrm{mi}}\right)$ thermal mass nodes. $\mathrm{R}_{\text {mee }}, \mathrm{R}_{\mathrm{mei}}$ and $\mathrm{R}_{\mathrm{mii}}$ consider both the convective and conductive heat transfer phenomena between the indoor air node and the building envelope. Details about the features of the building and the numerical values of the system parameters are reported in Section 3 where the case study is introduced.

The building model is subject to two heat fluxes, directly applied to the internal thermal nodes $\left(T_{\mathrm{a}}\right)$ : the heating power derived by the heating system ( $\left.Q_{\text {heating }}\right)$ and the heat gains due to solar radiation $\left(Q_{\text {solar }}\right)$.

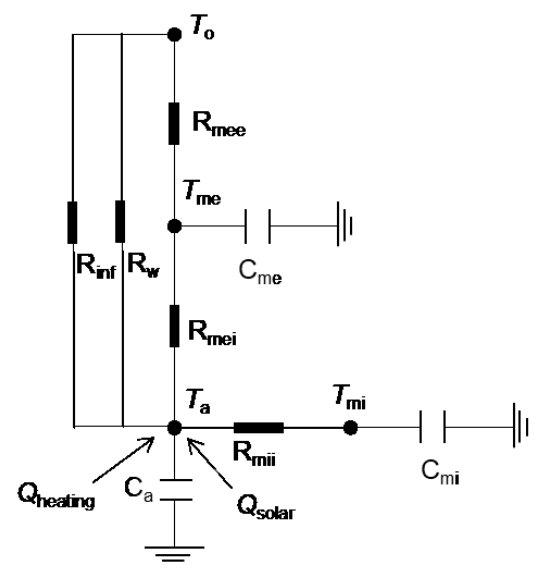

Fig. 1. Third order RC-Thermal network to modelling the energy demand of the single user.

Whit this architecture, the building demand can be represented with a linear state space formulation (Equations 1 and 2):

$$
\begin{gathered}
\forall k: \quad \boldsymbol{X}_{k+1}=\mathrm{A} \cdot \boldsymbol{X}_{k}+\mathrm{B} \cdot \boldsymbol{U}_{k} \\
\forall k: \quad \boldsymbol{Y}_{k}=\mathrm{C} \cdot \boldsymbol{X}_{k}+\mathrm{D} \cdot \boldsymbol{U}_{k}
\end{gathered}
$$

with the vector $\boldsymbol{X}=\left[T_{\mathrm{a}} T_{\mathrm{me}} T_{\mathrm{mi}}\right]^{\mathrm{T}}$ that represent the state of the system at each timestep $k$, $\boldsymbol{U}=\left[T_{\mathrm{o}} Q_{\text {heating }} Q_{\text {solar }}\right]^{\mathrm{T}}$ the input vector and $\boldsymbol{Y}$ the vector contains the outputs. A, B, C and D are time-invariant real matrices depending on the parameters of the system.

To validate the short-term energy simulation of the RC-network, it is compared with the results of a building model with the same thermal and geometrical characteristics, realized with a widely used software for dynamic energy simulations: TRNSYS [13]. 


\subsection{Heating system}

As showed in Figure 1, the contribution of the heating system $\left(Q_{\text {heating }}\right)$ is directly applied to the indoor air node $\left(T_{\mathrm{a}}\right)$. In this way, no thermal inertia is assigned to it. An air source heat pump is modelled in order to obtain the electricity demand to be managed. In particular, the performance of a commercial heat pump is extrapolated by a manufacture catalogue [14]. Since the detailed representation of the distribution system is not considered, the COP depends only on the outdoor air temperature $\left(T_{\mathrm{o}}\right)$.

For the state space formulation (Equations 1 and 2), the heating power ( $Q_{\text {heating }}$ ) has to be provided as an input for the building model. However, to test DR strategies, it is necessary that the electricity demand (El) derived by TCL becomes an adjustable variable. For this reason, an optimization problem is introduced. The optimization has the objective to minimize the thermal requirements of the building while comfort conditions are maintained.

The minimization problem can be written as:

$$
\min \sum_{k=1}^{\mathrm{d}} Q_{\text {heating }}(k)
$$

subject to the following constraints:

$$
\begin{gathered}
\forall k: \quad \mathrm{T}_{\min } \leq T_{\mathrm{a}}(k) \leq \mathrm{T}_{\max } \\
\forall k: 0 \leq Q_{\text {heating }}(k) \leq \mathrm{Q}_{\max }
\end{gathered}
$$

where $\mathrm{T}_{\min }$ and $\mathrm{T}_{\max }$ define the comfort band for the users and $\mathrm{Q}_{\max }$ the heat pump size.

The energy behaviour of the building is added to the optimization problem as a set of constrains, one for each time step $k$ (Equation 4 ). On the contrary, the heating demand, $Q_{\text {heating }}(k)$, becomes the decision variable of the problem and, through the $C O P$, it can be connected to the electricity demand of the user $\left(P_{\mathrm{u}}\right)$, which represents the TCL to be managed during the DR event.

$$
P_{\mathrm{u}}=\frac{Q_{\text {heating }}(k)}{\operatorname{COP}(k)}
$$

For its linear characteristics, the optimization problem can be solved for the duration of the simulation (d) as a typical Linea Programming (LP) problem.

\subsection{Demand response event}

To evaluate the energy flexibility of a buildings cluster a DR event is introduced. It consists of a peak-shaving strategy to produce a controlled hourly reduction of the electricity demand of a group of users. A reference scenario is introduced to reveal the time location of the peak. It is obtained in case of fixed set-point temperature, $\mathrm{T}_{\mathrm{SP}}$ (referring to Equation 4: $\mathrm{T}_{\min }=\mathrm{T}_{\max }=\mathrm{T}_{\mathrm{SP}}=20^{\circ} \mathrm{C}$ ) for all the users involved in the cluster. Then, in the form of an additional constraint for the optimization problem, the aggregated electricity demand is forced to an established percentage reduction in the reference case peak-hour. The additional constraint is formulated in Equation 7 where $\mathrm{N}$ is the number of users composing the cluster, $\mathrm{f}_{\mathrm{r}}$ is the peak electricity power $\left(\mathrm{P}_{\max }\right)$ reduction factor.

$$
\forall u: 0 \leq \sum_{u}^{\mathrm{N}} P_{u}(k) \leq \mathrm{f}_{\mathrm{r}} \cdot \mathrm{P}_{\max }
$$


Since the energy flexibility has to be activated when the DR event is realized, a tolerance of $2{ }^{\circ} \mathrm{C}$ is allowed for the comfort constraints in the optimization problem. As anticipated in Section 1, different user compositions in the cluster are evaluated: they are differentiated by the occupancy profiles, defined by means of daily set-point temperature profiles $\left(T_{\mathrm{SP}}(k)\right)$ for the heating system. In this way, Equation 4 can be rewritten as:

$$
\begin{aligned}
& \forall k: T_{\text {max }}=T_{\mathrm{SP}}(k)+1^{\circ} \mathrm{C} \\
& \forall k: T_{\text {min }}=T_{\mathrm{SP}}(k)-1^{\circ} \mathrm{C}
\end{aligned}
$$

\section{Case study}

A single-family house of $100 \mathrm{~m}^{2}$, located in Milan, Italy $\left(45^{\circ} 27^{\prime} \mathrm{N}, 9^{\circ} 11^{\prime} \mathrm{E}\right)$ is considered as case study. Its thermal properties are extrapolated from Tabula Project [15] for the most updated buildings (from 2006 onwards). The thermal transmittances values are: $0.34 \mathrm{~W} \mathrm{~m}^{-2}$ $\mathrm{K}^{-1}$ for external walls, $0.28 \mathrm{~W} \mathrm{~m}^{-2} \mathrm{~K}^{-1}$ for the roof, $0.33 \mathrm{~W} \mathrm{~m}^{-2} \mathrm{~K}^{-1}$ for the floor and $2.20 \mathrm{~W}$ $\mathrm{m}^{-2} \mathrm{~K}^{-1}$ for the windows. An air change per hour (ACH) of $0.2 \mathrm{~h}^{-1}$ is considered. With reference at the typical building surfaces compositions reported in [16], the values of the RCnetwork parameters are summarized in Table 1.

Table 1. Third order RC-Thermal network to modelling the energy demand of the single user.

\begin{tabular}{|c|c|}
\hline $\mathrm{C}_{\mathrm{me}}\left(\mathrm{J} \mathrm{K}^{-1}\right)$ & $69.5 \cdot 10^{6}$ \\
\hline $\mathrm{C}_{\mathrm{mi}}\left(\mathrm{J} \mathrm{K}^{-1}\right)$ & $44.0 \cdot 10^{6}$ \\
\hline $\mathrm{C}_{\mathrm{a}}\left(\mathrm{J} \mathrm{K}^{-1}\right)$ & $0.73 \cdot 10^{6}$ \\
\hline $\mathrm{R}_{\text {mee }}\left(\mathrm{K} \mathrm{W}^{-1}\right)$ & $2.6 \cdot 10^{-3}$ \\
\hline $\mathrm{R}_{\text {mei }}\left(\mathrm{K} \mathrm{W}^{-1}\right)$ & $6.8 \cdot 10^{-3}$ \\
\hline $\mathrm{R}_{\mathrm{mii}}\left(\mathrm{K} \mathrm{W}^{-1}\right)$ & $1.8 \cdot 10^{-3}$ \\
\hline $\mathrm{R}_{\text {inf }}\left(\mathrm{K} \mathrm{W}^{-1}\right)$ & 0.0246 \\
\hline $\mathrm{R}_{\mathrm{w}}\left(\mathrm{K} \mathrm{W}^{-1}\right)$ & 0.019 \\
\hline
\end{tabular}

According to [17], for a design outside temperature of $-5{ }^{\circ} \mathrm{C}$ [18], a maximum heating load of $3.5 \mathrm{~kW}$ is calculated to maintain an indoor comfort condition of $20^{\circ} \mathrm{C}$. This value is assumed as $\mathrm{Q}_{\max }$ in Equation 5. The inputs of the state space model ( $T_{\mathrm{o}}$ and $Q_{\text {solar }}$ in Equations 1 and 2) are obtained from a Typical Meteorological Year (TMY) for the city of Milan [19].

To validate the RC-model, it is compared to a building with the same features modelled with Type 56 in TRNSYS. Figure 2 shows the comparison of the indoor temperature in a week without providing heating power $\left(Q_{\text {heating }}(k)=0 \mathrm{~kW}\right)$.

As mentioned in Section 2.3, users that differ in occupancy profile are considered in the cluster. In particular three kinds of behaviour are considered: user $\mathrm{U}_{1}$ with a fixed set point of $20^{\circ} \mathrm{C}$ (reference scenario), user $\mathrm{U}_{2}$ with a set-point of $20^{\circ} \mathrm{C}$ from $8.00 \mathrm{am} 9.00 \mathrm{am}$, from $12.00 \mathrm{pm}$ to $2.00 \mathrm{pm}$ and from $7.00 \mathrm{pm}$ to $9.00 \mathrm{pm}$ and $\mathrm{U}_{3}$ with the set-point equal to $20{ }^{\circ} \mathrm{C}$ from $8.00 \mathrm{am} 9.00 \mathrm{am}$ and from $7.00 \mathrm{pm}$ to $9.00 \mathrm{pm}$ (in the remaining hours the set point is lowered to $18{ }^{\circ} \mathrm{C}$ both for $\mathrm{U}_{2}$ and $\mathrm{U}_{3}$ ). In Figure 3 the daily users' profiles are showed. 


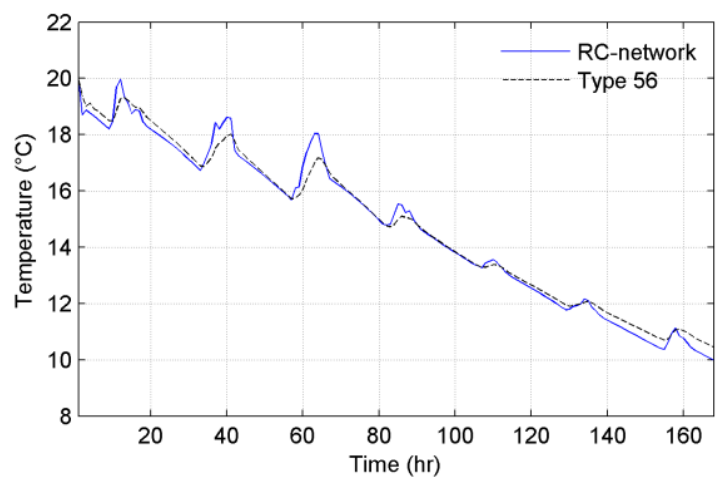

Fig. 2. Comparison between TRNSYS Type 56 and RC-network $\left(\mathrm{RMSE}=0.31^{\circ} \mathrm{C}\right)$.

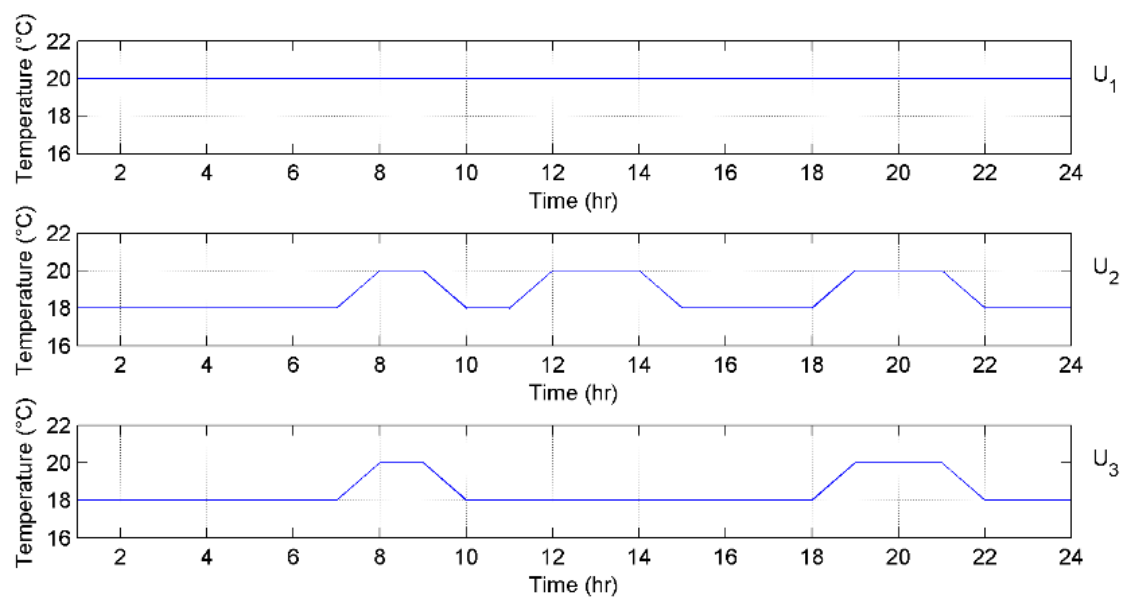

Fig. 3. Users occupancy profiles.

\section{Results}

As described in Section 2.3, a daily peak-shaving event is tested. For this reason, results are showed in a representative winter day (14 January). Compared to the reference scenario, Figure 4 shows the application of the DR event to a single building (occupancy profile $U_{1}$ in Figure 3). Looking at the black dotted curve in Figure 4b, an electricity peak can be observed at $10.00 \mathrm{am}$. Therefore, the DR event imposes a power reduction from 10.00 am to 11.00 , allowing an enhanced exploitation of the comfort band. In particular a half reduction of the power is enforced $\left(f_{r}=50 \%\right.$, Equation 7$)$ in the case showed in Figure 4.

In order to maintain the comfort a pre-heating strategy is necessary to reduce the power consumption during peak time (blue continuous line in Figure 4a). As a consequence, an anticipated electricity peak occurs at 9.00 am with even a greater value in amplitude to account for thermal losses. The peak value passes, in fact, from $0.97 \mathrm{kWe}$ in reference operation to $1.3 \mathrm{kWe}$ with the DR event (increase of $+37 \%$ ). It seems clear that, despite the objective of the event is achieved, a drawback effect connected to it occurs in the previous hours. 

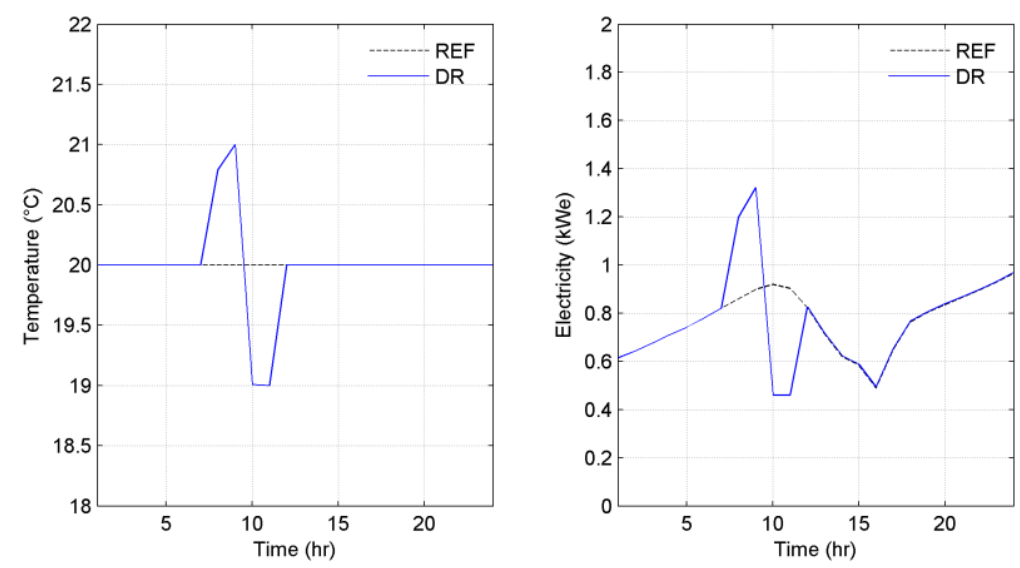

Fig.4. Comparison between reference operation (REF) and DR event for a single user $\left(\mathrm{U}_{1}\right)$. (a) Indoor air temperature $\left(T_{\mathrm{a}}\right)$; (b) Electricity demand $\left(P_{\mathrm{U} 1}\right)$.

When multiple users are aggregated in a cluster, a careful planning of users' participation can allow the event to take place without unexpected load peaks. No improvement compared to case showed in Figure 4 can be observed if users with the same behaviour are involved, but the electricity demand of the cluster is only scaled compared to the number of users participating. Therefore, a great contribution can be made by the engagement of users with different occupancy behaviours. In Figure 5 a small cluster composed of three users is subject to the peak-shaving event in the same day. Two of the three users have the reference scenario occupancy profile $\left(U_{1}\right)$, while the third acts as $U_{2}$ (Figure 3 ). In this case the anticipated peak no longer appears, while another one appears postponed at $12.00 \mathrm{pm}$. There is, however, no amplification of the peak value, which remains of the same order of magnitude as the reference case $(2.76 \mathrm{kWe}$ in reference scenario and $2.86 \mathrm{kWe}$ in case of DR event). Another increase in consumption is also recorded in the evening hours (from $7.00 \mathrm{pm}$ to $9.00 \mathrm{pm}$ ). Anyway, it is not related to the DR event but to the set-point temperature of user $\mathrm{U}_{2}$ rising.

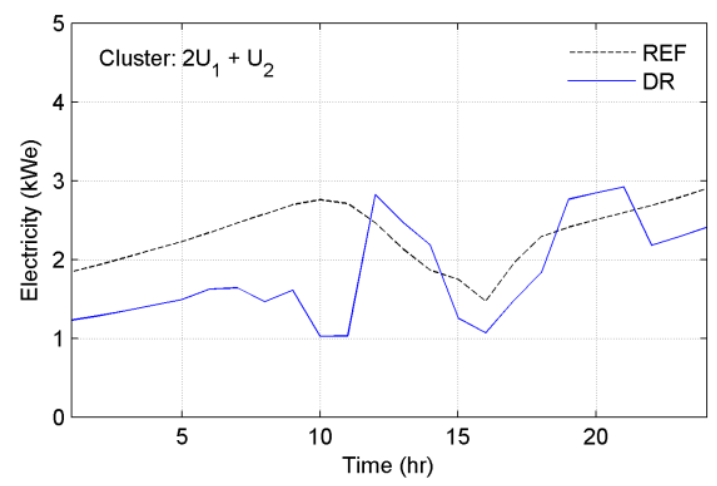

Fig.5. Comparison between reference operation (REF) and DR event three users cluster: 2 users $U_{1}$ and 1 user $\mathrm{U}_{2}$. 


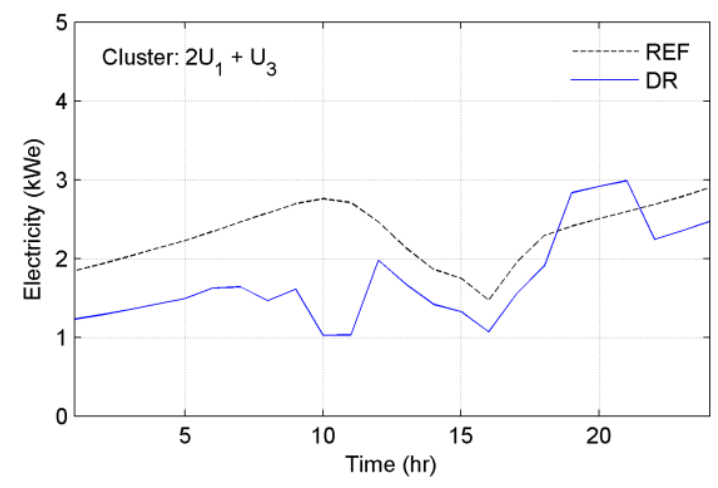

Fig.6. Comparison between reference operation (REF) and DR event three users cluster: 2 users $U_{1}$ and 1 user $\mathrm{U}_{3}$.

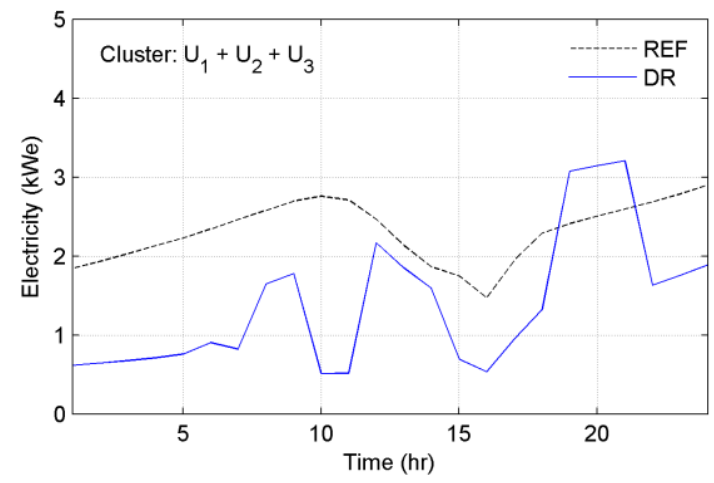

Fig.7. Comparison between reference operation (REF) and DR event three users cluster: 1 user $\mathrm{U}_{1}, 1$ user $\mathrm{U}_{2}$ and 1 user $\mathrm{U}_{3}$.

Further improvements can be observed when also user $U_{3}$ is involved in the cluster. Figures 6 and 7 show this behaviour. Figure 6 presents the same case represented in Figure 5 in which the user $U_{2}$ is replaced by $U_{3}$, while in Figure 7 all the users $\left(U_{1}, U_{2}\right.$ and $\left.U_{3}\right)$ are involved. Both the clusters tested (Figures 6 and 7) allow to cut the peak avoiding drawback effects both in the hours before and after the DR event. Due to the change of the occupancy profile between $7.00 \mathrm{pm}$ to $9.00 \mathrm{pm}$, also in this case an increase in the electricity consumption respect to the reference operation is observed.

Focussing only on the hours before and after the event, the presence of a user $\mathrm{U}_{3}$ appears fundamental to avoid new power peaks, keeping the demand curve below the reference scenario. This behaviour is also confirmed if larger clusters are tested. In this case, it is possible to connect the minimum number of users $\mathrm{U}_{3}$ to be involved to avoid such unexpected peaks. In particular, when a peak halving is required $\left(f_{r}=50 \%\right)$, the $8 \%$ of the users should have an occupancy profile as $\mathrm{U}_{3}$. 


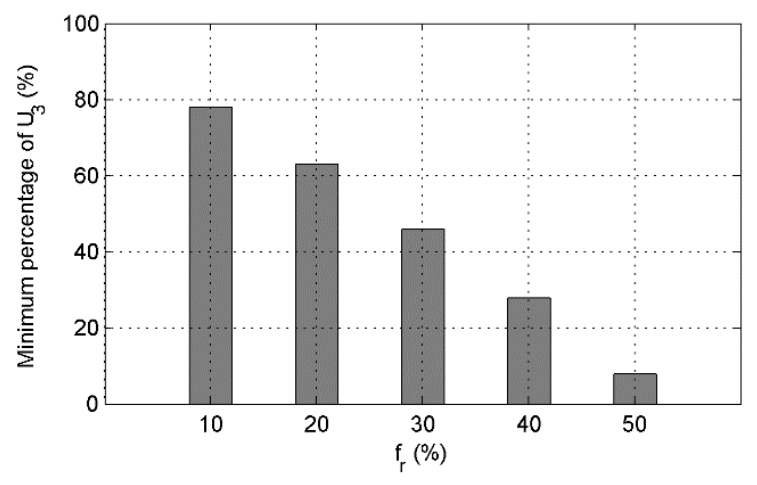

Fig.8. Percentage of the minimum number of users $U_{3}$ to be involved in a peak-shaving event to produce different peak reduction $\left(f_{r}\right)$ avoiding drawback effects connected to it in the hours before and after the event.

Figure 8 shows the percentage of user $\mathrm{U}_{3}$ involvement in case of different peak power reductions $\left(\mathrm{f}_{\mathrm{r}}\right)$ required by the DR event. A high participation (minimum $78 \%$ ) is necessary if the peak wants to be reduced to $10 \%$, then the percentage decreases as $f_{r}$ increases.

From this last consideration it is evidenced even more the role of a differentiated cluster of users when the energy flexibility wants to be used for load shifting strategies. Thanks to the differentiation of behaviour, the energy flexibility acquires more degrees of freedom, allowing to perform DR events by minimizing the presence of undesirable effects connected to it.

\section{Conclusions}

In this paper an analysis about the energy flexibility obtainable by the management of the TCL of residential buildings clusters in provided. To do that, buildings with the same construction features and different occupancy profiles are combined in clusters subject to a DR event based on a peak-shaving strategy. Results show that, often drawback (anticipated or participated peaks) effects occur when no thermal inertia is provided by the distribution system and the DR objective is achieved with a pre-heating strategy. However, a careful planning of the residential cluster only based on the occupancy profile of users can have positive effects in this regard. If at least the $8 \%$ of users composing the cluster has an occupancy profile for which it is expected a lowering of the set-point in the hours close to the event (user $\mathrm{U}_{3}$ ), a peak reduction to $50 \%$ can be easily obtained without the formation of undesired new peaks. The percentage increase as the programmed reduction increase, arriving to request a presence of at least $78 \%$ of users $U_{3}$ to reduce it to $10 \%$ of its value.

The case tested in this paper shows that combined flexibility allows multiple degrees of freedom to apply DR events in residential building cluster, showing the potential of a planned composition of users to be involved to avoid rebound effects in the demand curve.

This research was funded by the Italian Ministero dell'Istruzione, dell'Università e della Ricerca (MIUR) within the framework of PRIN2015 project "Clean Heating and Cooling Technologies for an Energy Efficient Smart Grid”, Prot. 2015M8S2PA.

\section{References}

1. L. Gelazanskas, K.A.A. Gamage, Demand side management in smart grid: A review and proposals for future direction, Sustain. Cities Soc. (2014). 
https://doi.org/10.1016/j.scs.2013.11.001

2. IEA, The Critical Role of Buildings. Perspectives for the Clean Energy Transition. Report., (2019)

3. S.Ø. Jensen, A. Marszal-Pomianowska, R. Lollini, W. Pasut, A. Knotzer, P. Engelmann, A. Stafford, G. Reynders, IEA EBC Annex 67 Energy Flexible Buildings, Energy Build. (2017). https://doi.org/10.1016/j.enbuild.2017.08.044

4. H. Hao, B.M. Sanandaji, K. Poolla, T.L. Vincent, Aggregate flexibility of thermostatically controlled loads, IEEE Trans. Power Syst. (2015). https://doi.org/10.1109/TPWRS.2014.2328865

5. D. Fischer, H. Madani, On heat pumps in smart grids: A review, Renew. Sustain. Energy Rev. (2017). https://doi.org/10.1016/j.rser.2016.11.182

6. G. Reynders, R. Amaral Lopes, A. Marszal-Pomianowska, D. Aelenei, J. Martins, D. Saelens, Energy flexible buildings: An evaluation of definitions and quantification methodologies applied to thermal storage, Energy Build. (2018). https://doi.org/10.1016/j.enbuild.2018.02.040

7. F. D'Ettorre, M. De Rosa, P. Conti, D. Testi, D. Finn, Mapping the energy flexibility potential of single buildings equipped with optimally-controlled heat pump, gas boilers and thermal storage, Sustain. Cities Soc. (2019). https://doi.org/10.1016/j.scs.2019.101689

8. A. Arteconi, A. Mugnini, F. Polonara, Energy flexible buildings: A methodology for rating the flexibility performance of buildings with electric heating and cooling systems, Appl. Energy. (2019). https://doi.org/10.1016/j.apenergy.2019.113387

9. W.J.N. Turner, I.S. Walker, J. Roux, Peak load reductions: Electric load shifting with mechanical pre-cooling of residential buildings with low thermal mass, Energy. (2015). https://doi.org/10.1016/j.energy.2015.02.011

10. M. Hu, F. Xiao, Quantifying uncertainty in the aggregate energy flexibility of high-rise residential building clusters considering stochastic occupancy and occupant behavior, Energy. (2020). https://doi.org/10.1016/j.energy.2019.116838

11. P. Bacher, H. Madsen, Identifying suitable models for the heat dynamics of buildings, Energy Build. (2011). https://doi.org/10.1016/j.enbuild.2011.02.005

12. Un.E. ISO, UNI EN ISO 13790. Energy performance of buildings Calculation of energy use for space heating and cooling, (2008) 1-24

13. T. energy system Specialists, TRNSYS Software

14. Viessmann, VITOCAL 200-S AWB/AWB-AC 201.B04/ .B07/ .B10 / .B13 /.B16. Commercial datasheet catalogue., (2017)

15. V. Corrado, I. Ballarini, S.P. Corgnati, Typology Approach for Building Stock: D6.2 National scientific report on the TABULA activities in Italy, 2012

16. UNI/TR 11552, Opaque envelope components of buildings Thermo-physical parameters, (2014) 1-44

17. UNI/TS 11300-1, Energy performance of buildings Part 1: Evaluation of energy need for space heating and cooling, (2014)

18. UNI/TR, 10349-2. Heating and cooling of buildings - Climatic data - Part 2: Data for design load., (2016)

19. Meteotest, Meteonorm Software 